\title{
ESP32 Based Implementation of Water Quality and Quantity Regulating System
}

\author{
T. Sandeep Rao ${ }^{1}$, Pawan Pranay ${ }^{2}$, Sriman Narayana ${ }^{3}$, Yamunadhar Reddy $^{4}$, Sunil $^{5}$, \\ Pawandeep Kaur,**
}

1,2,3,4,5 Electronics Engineering Graduates, Lovely Professional University, Jalandhar, Punjab, India

${ }^{6}$ Electronics Engineering Department, Lovely Professional University, Jalandhar, Punjab, India

${ }^{*}$ Corresponding author. Email: pawandeep.kaur@lpu.co.in

\begin{abstract}
The primary purpose of this paper is to reduce the wastage of water. The former way of water testing is manual, costly, time consuming, whereas proposed work is easy to install and cost effective. The proposed work is focused on water quality and quantity measurements by using ESP32 microcontroller and Blynk for communication between hardware and phone. Water quality is monitored by the various chemical parameters of water like $\mathrm{pH}$ and electrical conductivity and physical parameters of water like turbidity and temperature. In addition, the quantity of water is measured by flow sensor and water level present in the tank is control by admin through the pump. Global Positioning System (GPS) is used to update the location of the water tank to save time and speedy maintenance. The result shows a good agreement with the standard values of parameters as per World Health Organization (WHO).
\end{abstract}

Keywords: ESP32 microcontroller, Internet of Things, Water Flow, Water Quality, Water Quantity.

\section{INTRODUCTION}

With the rapid evolution of society and population increase, water requirements have become a significant issue, particularly in the industrial, household, urban areas, farming, fish cultivation, and other areas. The significant issues are effective utilization of water and increasing contamination level of water in localities. The bacterial contamination of water is reported due to blooming industrialization and pollution [1]. The traditional methods are complicated in methodology, low precision, external electrodes or probes in situ based are high cost and lack of real data transportation and analyzing $[2,3]$. The essential goal of this work is to propose a model for monitoring water quality and quantity in municipal overhead tanks, in housing societies, in universities, etc. It is based on checking the most important physical and chemical parameters like temperature, turbidity, $\mathrm{pH}$ (potential of hydrogen), and conductivity. To enhance the effective utilization of water by consumers or localities, the admin controls the water consumption and remotely monitors the water level in tanks. Water resources can be managed depending on the time interval and necessity of the admin. This system is time-saving and cost-effective in environmental situations. Numerous recent technological advancements in microcontroller and microcomputer, sensor technology, communication devices, large data storages have made feasible the implementation of the low-cost models or systems using IoT $[4,5]$. Thus, the proposed work's primary focus is on testing water quality and automating the water quantity to save water, which is essential as per the growth pace of the population. ESP32 (Espressif System) used in this work has the advantages of high frequency, low cost, build in sensors (temperature, hall effect sensors like touch sensors), Wi-Fi and Bluetooth both integrations are present, speed upto $150 \mathrm{Mbps}, 10$ pin ADC, power management module, low noise amplifier receiver, security, filtering, etc. and easy to install. All the updated techniques have used both amalgamations of IoT and WSN to perform both functions of testing and controlling water, along with effective routine service with the help of GPS in cities or societies to assist the maintenance of tanks and cleaning services on time. The following section 2 includes the literature review of a set of paper based on controller, hardware, software, and parameters used for testing water are highlighted. Section 3 is composed of methodology having subsections like flow-graphs 
hardware and simulation setup, measuring the physical and chemical parameters by using ESP32 with Blynk connection. The standard range of various water parameters is present in table 1 . The results are discussed in section 4 and compared with the existing work shown in table 2, following the conclusion.

\section{LITERATURE SURVEY}

The reported work is based on temperature monitoring of water by using mobile so that cycle of fish production and growth can be monitored along with the measurements of temperature ranges from normal to maximum value with the help of controller in real time [6]. The literature recorded $[7,8]$ focused on sea water and sensors are used to measure temperature, $\mathrm{PH}$, ORP and conductivity. The hardware is based on ATmega1281 and frequency of $8 \mathrm{MhZ}$ used for implementation. The other work used LPC1768 ARM MCU with GPS to monitor water in rivers and lakes. The additional parameters are carbon monoxide, and humidity. Similar sort of work on lakes and rivers performed by [9] using LPC2148 along with ESP8266 Wi-Fi data for transmission and reception and LCD as hardware to display data. The Arduino board is embedded with sensors like temperature, $\mathrm{pH}$ and DO (dissolved oxygen) for analyzing water. All the above reported work is based on monitoring of water quality. In other approach [10] the reconfiguration concept is used with help of FPGA board to scan the turbidity, temperature, carbon dioxide by using BEE MCU and Zigbee, GSM hardware for transmission of data. In advancement of quality monitoring of water the security feature is introduced by [11]. In the recorded work interfacing done through Arduino board and sensors based on wireless sensor network (WSN) with Wi-Fi module. In [12] inaugurate the system that assist the farmers for quality water and Shrimp cultivation at Taipa using IOT. The main equipment used Atmega 2560, with Raspberry pi 3 based MQTT. For communication LoRa wireless interface is used. Sensors embedded in system monitoring are temperature, $\mathrm{pH}$, salinity. The work based advance techniques machine learning, deep learning with integration of Big data proposed by $[13,14]$.The work is based on monitoring of physical parameters like turbidity, $\mathrm{pH}$, temperature, salinity and total dissolved solids (TDS).the work is carried with Arduino board based on ATmega2560 microcontroller and WSN.FPGA based similar approached introduced by [15] along with Zigbee protocol for communication and both features water monitoring (temperature, turbidity and $\mathrm{pH}$ ) and water quantity as well. In this paper [16] author used the Arduino MCU for implementation of water quality monitoring using Wi-Fi and GSM .The chemical and physical parameters incorporate for research are temperature, $\mathrm{pH}$ level ,electric conductivity. Whereas the reported work in [17] add the water quality with IoT and wireless sensor network (WSN) platform which is for smart city, still scope of controlling the water quantity. There is advancement in communication of the monitored data remotely with the use of IoT [18].The water quality measurement is tested on two parameters and controlling the water utilization is not done. The recent work reported [19] IoT based using web server for Gouramy cultivation for water quality only.

\section{METHODOLOGY OF THE PROPOSED SYSTEM}

\subsection{System Architecture and Schematic circuit}

In this proposed system, figure 1 shows the architecture which depicts about the integration of sensors with ESP32 function as microcontroller and how the communication takes place between controller and the Blynk cloud. The sensors like DS18B20 for Temperature, Conductivity sensor, $\mathrm{pH}$ sensor, turbidity sensor, YF-S201 sensor for water flow, Dc pump, relay, Global Positioning System (GPS) and water level sensor are used [22-24].

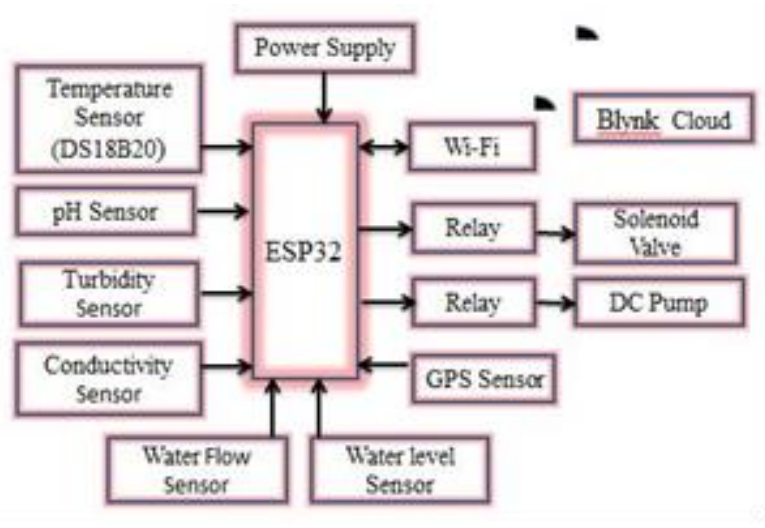

Figure 1 Proposed Architecture of Water Quality and Quantity Regulating System using ESP32

\subsection{Flow-graph}

In the following section the various flow graphs are shown for water analysing and actuating the pump as per requirement [25-29]. In figure 2 (a) first check the Wi-Fi connect and then flow of water of less than 1000 litre in tank then on the solenoid valve. Figure 2 (b) initializing the sensors ( $\mathrm{pH}$, conductivity temperature, turbidity) whereas in figure 2 (c) send the alerts and automatic control of tank valve if quality of water for measured parameters are under threshold as shown in flow graph. The municipal water tank level is measured and control in accordance with if level of water less than 30 meter on the valve to fill the tank again otherwise off the pump. After sensing measurements all the data updates on cloud once the upload interval passed that means after every 2 second [30]. 


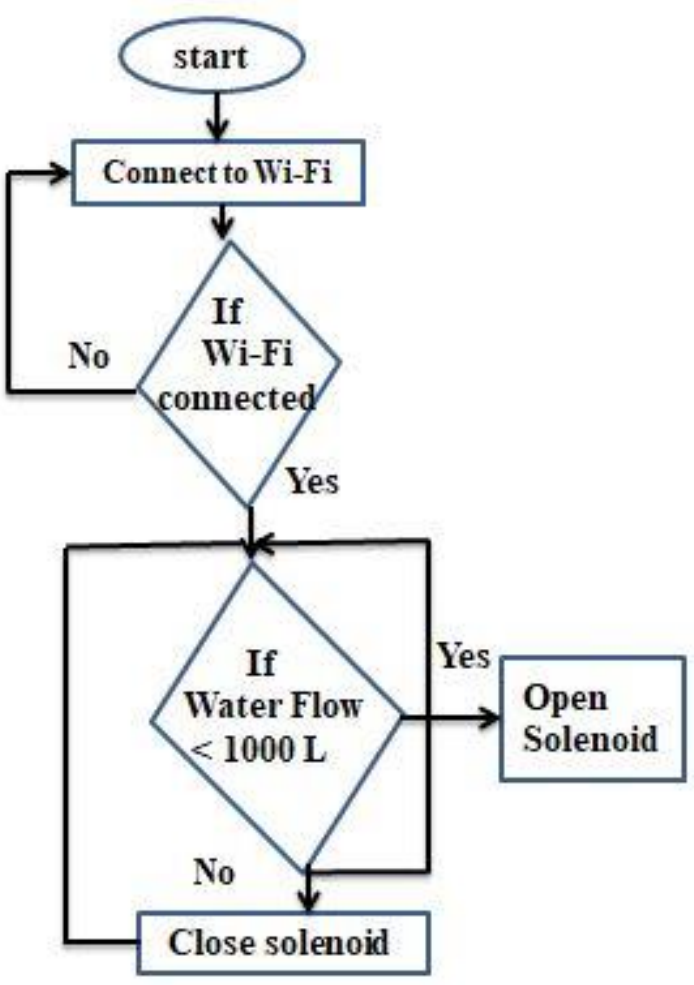

Figure 2(a) Connection to Wi-Fi and water flow control

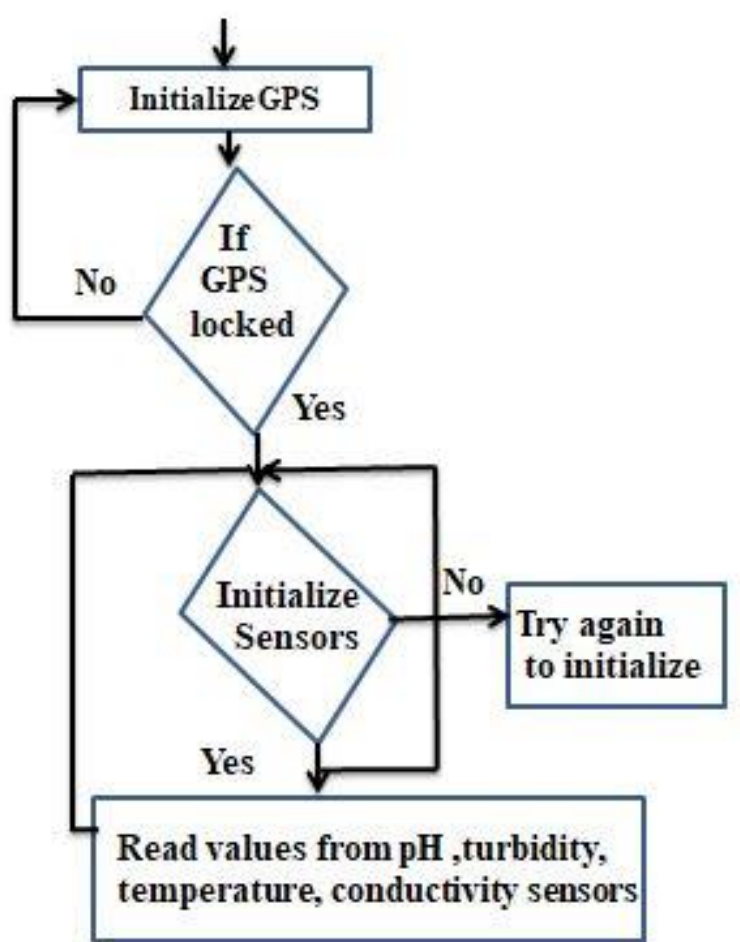

Figure 2(b) Initializing the Sensors

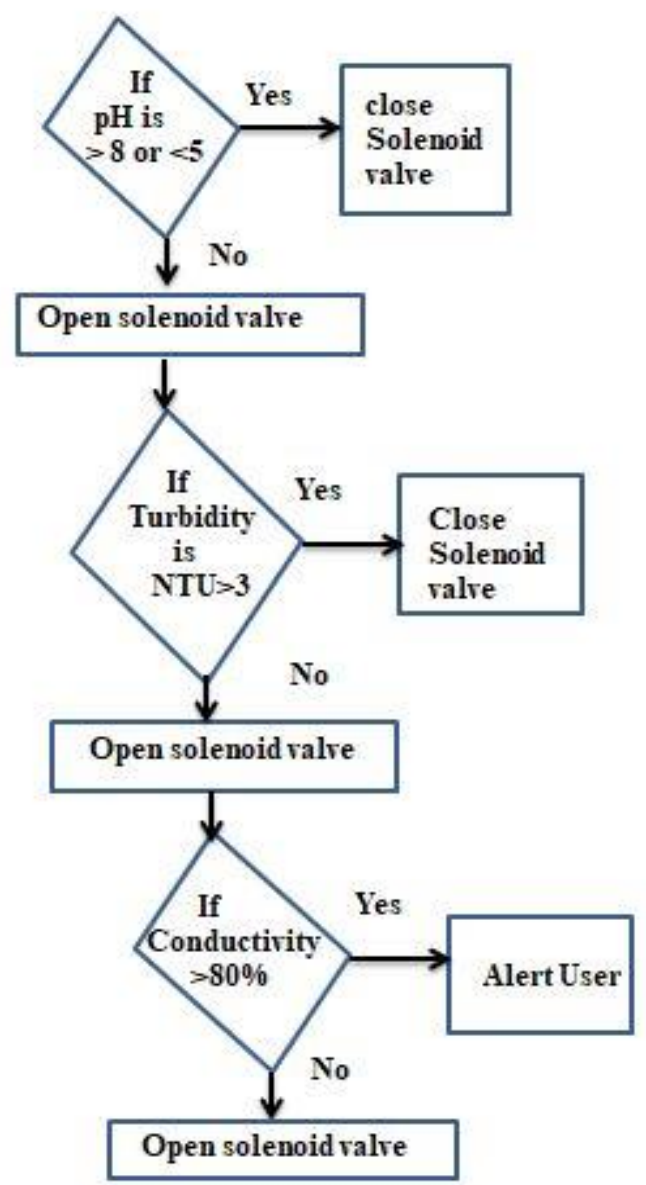

Figure 2(c) Working of Water Quality Sensor

\subsection{Sensors}

\subsubsection{Turbidity}

Sensor is basically used to measure the water quality in terms of coherent water and total suspended solids in water (TSS) [31]. Dinky water contains an enormous number of suspended particles. The turbidity sensor has infrared light emitting diode (IR LED) and a photodiode in its probes. The basic principle is when light from LED falls on water and scatter due to solid particles in water. In digital signal mode, the threshold can be adjusted by potentiometer. Turbidity increases with increase of solid particles in water. The turbidity of water ranges from $(0-1000)$ NTU in which $(<5)$ represents the clear water [32].

\subsection{2 $p H$}

The $\mathrm{pH}$ sensor estimates the activity of hydrogen particles in liquids. It has two probes bronze and silver with different diameter having difference between probes as $1.2 \mathrm{~cm}$. It is based on the principle that an interface of two liquids generates the potential difference which can be recorded. In this event the 
convergence of hydrogen particles inside the aqueous solution is not the same that results the potential difference on glass electrode and calomel reference electrode. The $\mathrm{pH}$ level of drinking water should be between the range of $6.5-8.5$.

\subsubsection{Temperature}

The significance of temperature measurement under the physical analysis of water quality is to measure locality water according to proposed work. The sensor model is DS18B20 water proof in built 12-bit ADC, (conversion done with convert-T command) used to communicate with ESP32 over one wire bus communication having power supply range from $3 \mathrm{~V}$ to $5.5 \mathrm{~V}$ [33-35]. The operating temperature range is $-55^{\circ}$ to $+125^{\circ} \mathrm{C}$ with accuracy of $+/-0.5^{\circ} \mathrm{C}$.

\subsubsection{Conductivity sensor}

The conductivity sensor computes the ability of water to induce electric current or not. It is the existence of ions in a solution that concede the solution to act as conductive more the concentration of ions, then higher is the conductivity. Higher the conductivity indicates lower the quality of water. As the resistance is reciprocal of conductivity if less ions means more resistance and less conductivity which indicates the purity level of water.

\subsubsection{Flow sensor}

The water management can be done through water flow sensor YF-S201 model of $1 / 2$ inch is used for exaggerated utilization of water in localities at consumer end. This sensor has 3 pin for interfacing with ESP32. Two pins for biasing as $5 \mathrm{~V} \mathrm{VCC}$ and Gnd. It consists of water rotor and hall-effect sensor when rotor rotates water flow through it and the speed alters according to rate of flow. The hall-effect sensor outputs the pulse signal. The output is in pulse which communicated with ESP32 and send signal to relay to cut the water supply through phone by admin. This is easy and cost effective approach to maintain water consumption.

Table 1 Quality Range of parameter by WHO [20] and EU standards [21]

\begin{tabular}{|l|l|l|l|}
\hline Sl. No. & Parameters & Units & Quality Range \\
\hline 1 & $\mathrm{pH}$ level & $\mathrm{pH}$ & $6.5-8.5$ \\
\hline 2 & Turbidity & NTU & $0-5$ \\
\hline 3 & Temperature & ${ }^{\circ} \mathrm{C}$ & --- \\
\hline 4 & $\begin{array}{l}\text { Electrical } \\
\text { Conductivity }\end{array}$ & $\mu \mathrm{S} / \mathrm{cm}$ & $50-1000$ \\
\hline
\end{tabular}

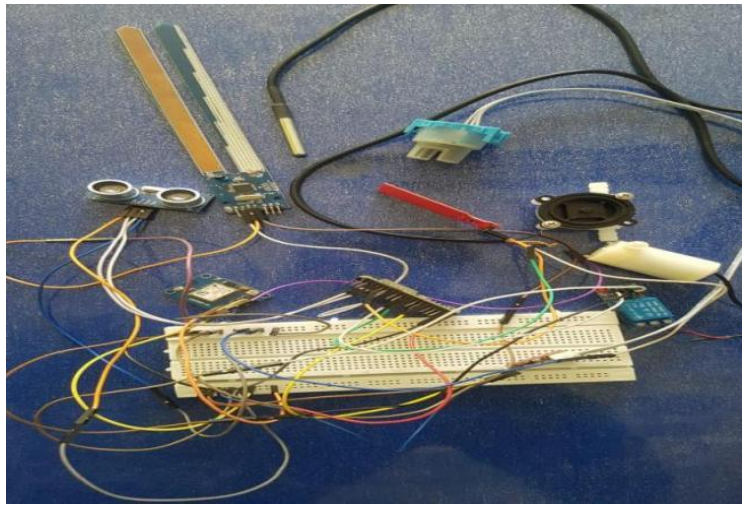

Figure 3 Hardware Connection of proposed Architecture

In figure 3 depicts the hardware connections of the proposed architecture. All sensors connected on breadboard.

\subsection{Software Requirements}

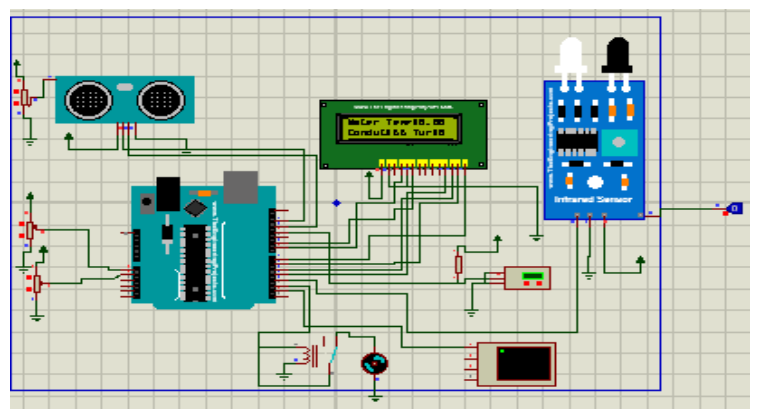

Figure 4 Simulation of proposed architecture

Simulation of the proposed architecture is performed in Proteus software as shown in figure 4. Proteus is open source software used to design the electronic circuits. Different sensors for water quantity as well as for water quality are used for simulation. In water quality we are regulating physical parameters of water like $\mathrm{PH}$, Temperature, Turbidity, electrical conductivity for this certain sensors are imported from library like DS18B20 sensor for measuring the temperature, variable resistors are used for measuring $\mathrm{pH}$ and conductivity. For measuring turbidity Infrared sensor is used. Regulating the level of water by importing ultrasonic sensor from the library. The deficiency of various sensors in Proteus library for measuring $\mathrm{pH}$ level, conductivity level and water flow, thus these parameters are not under simulation. For simulation in Proteus Arduino UNO controller is used instead of ESP32 because ESP32 is not available on Proteus library. In hardware implementation all the sensors are used and results are shown in next section.

\section{RESULTS DISCUSSION}

In result section, the obtained values of parameter are compared with the recorded literature and standard 
range mention in table1. Figure 5 shows how the communication connected using (Blynk). It depicts the controller is connected to hotspot. Second line states connected successfully. It shows the Internet Protocol address of the hotspot connected. Third statement indicates the controller model. After shows the connections successfully established between controller and Blynk cloud. Last ping is connection speed at which the data is transmitted to the Blynk Cloud. In the figure 6 there are 6 sensor values which have been displayed in 6 different virtual widgets the values belong to physical and chemical parameter along with water quantity. These values will update in every 2 seconds. Tap time ranges at the bottom of the widgets change time ranges Tap Legend Elements to show or hide DataStream's Quick swipe from left to right to reveal previous data Full Screen Mode Press arrow button to open Full Screen view in landscape orientation.

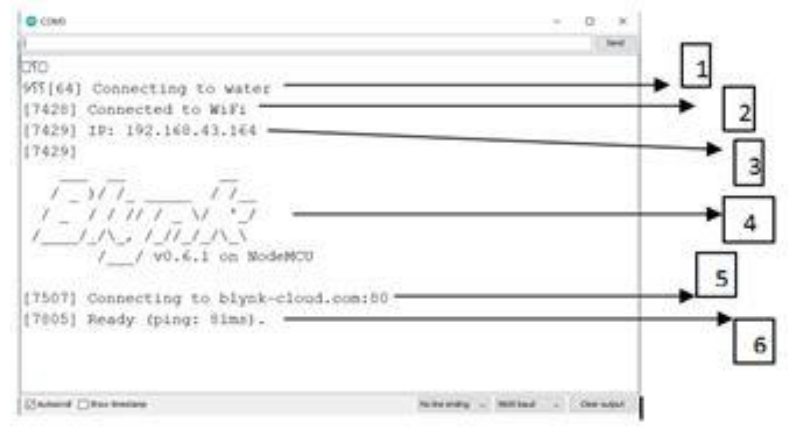

Figure 5 Blynk Connection

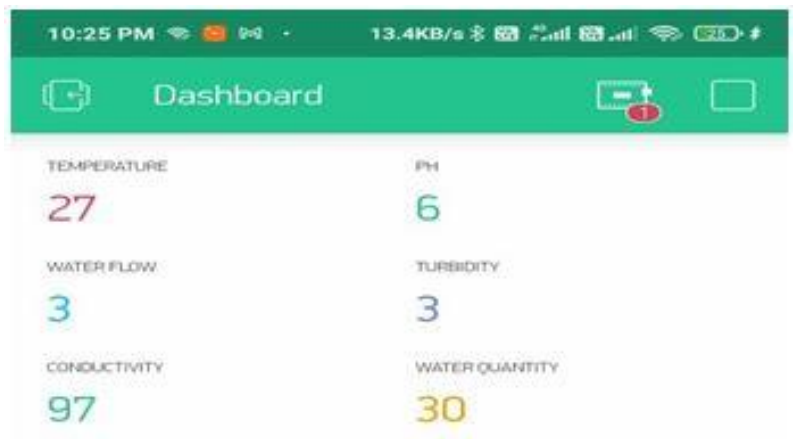

Figure 6 Output Values displayed on Blynk

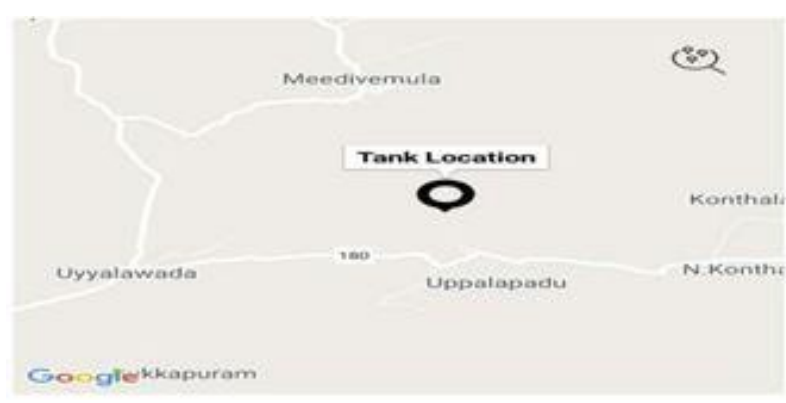

Figure 7 Tank Location displayed in Blynk
Figure 7 portray, water tank location for maintenance, easy to locate by service providers to provide services on time with the help of Global Positioning System (GPS). In the figure 8 the combined graph of all the physical and chemical parameters along with water flow and water quantity shown. In figure 9 the variation in temperature according to time period is shown the highest peak point in the graph is recorded at 27 degrees Celsius and the lowest peak point in the graph is recorded at -25 degrees celsius. The horizontal line represents stable temperature.
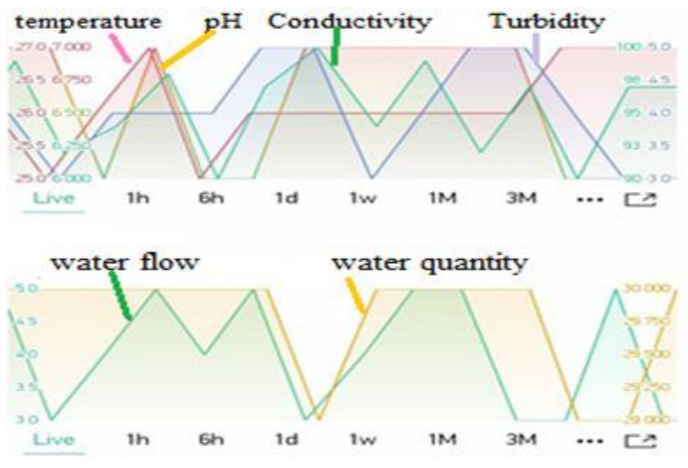

Time Axis

Figure 8 The Water Quality and Quantity graphs displayed in Blynk

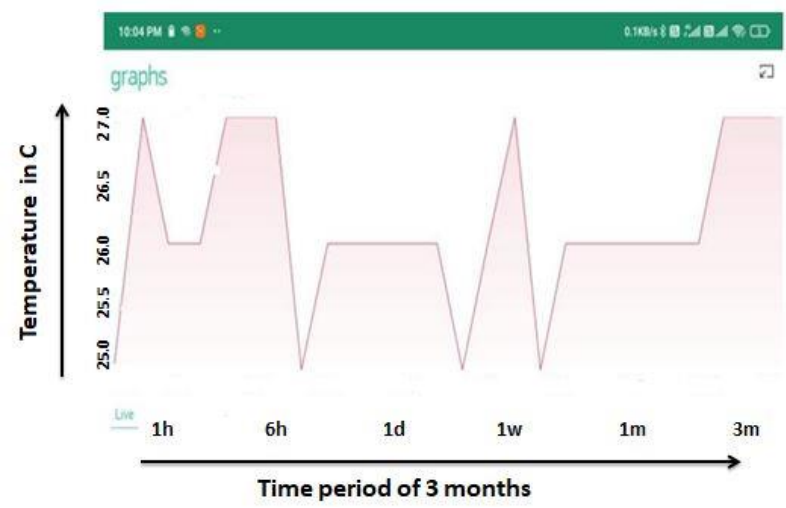

Figure 9 Temperature Data displayed in Blynk

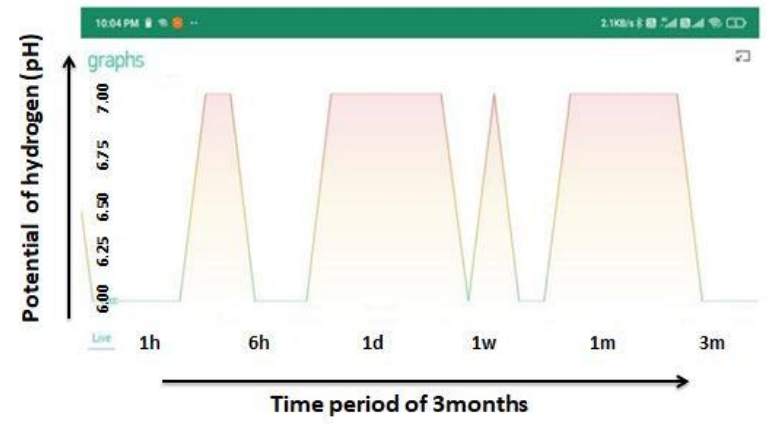

Figure 10 PH Data displayed in Blynk

In figure 10 reflects the $\mathrm{pH}$ versus time period of 3 months. Generally, the $\mathrm{pH}$ scale ranges from 0-14. 


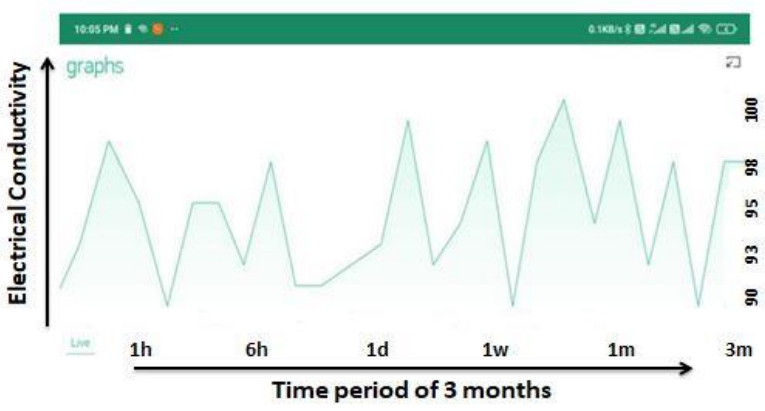

Figure 11 Electrical conductivity Data displayed in Blynk

The $\mathrm{pH}$ level of $(>7)$ represents the acidity in water and $\mathrm{pH}$ level of $(<7)$ represents the base nature in water. In the above graph the $\mathrm{pH}$ level of water is fluctuating between 6 to 7 that represents the normal water which can be consumable. In figure 11 represents how conductivity data has changed over time period of 3 months and generally the pure water represents $(0.055-$ $0.1) \mathrm{uS} / \mathrm{cm}$ and the distilled water represents from $(0.5-$ $3)$. In the above graph the water conductivity level ranges from (90-100) uS/cm which indicates the domestic "tap" water. Figure 12 gives turbidity variation with time period. Generally, the turbidity of water ranges from $(0-1000)$ NTU in which $(<5)$ represents the clear water. In the above graph the turbidity ranges from (3.0-5.0) NTU which represents the soft water.

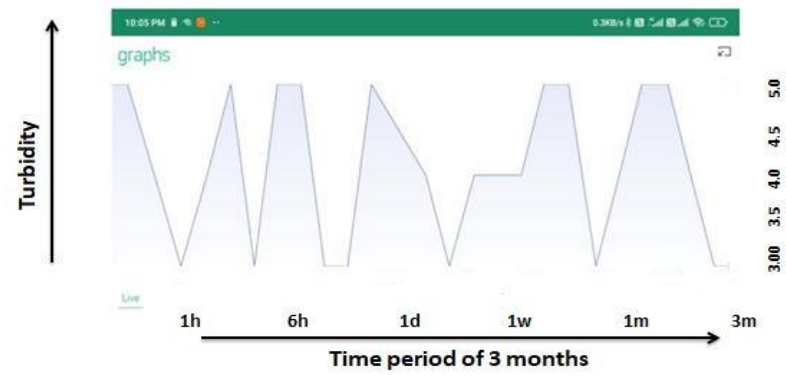

Figure 12 Turbidity Data displayed in Blynk

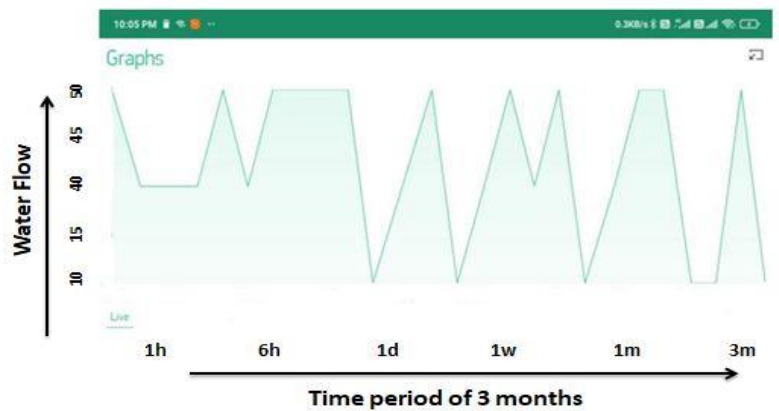

Figure 13 Water flow Data displayed in Blynk

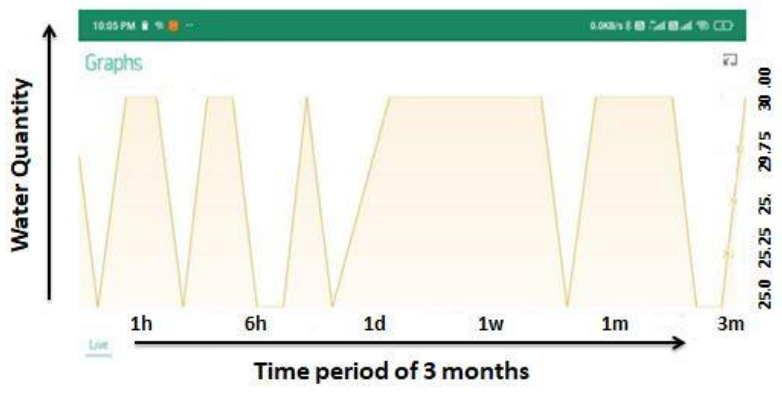

Figure 14 Water Quantity Data displayed in Blynk.

In Figure 13 represent how water flow data has changed over time period. In graph it is showing that how much water has been passed through water flow sensor i.e [30 to 50] ltrs. Figure 14 represent how water quantity data has changed over time period of 3 months. The Ultrasonic sensor will measure the distance of the water from the sensor if the distance is $(>30)$ metres, the controller sends the signal to relay which turn on the pump and if it is $(<30)$ metres then relay turn off the pump. In the above graph the water level is ranged from (29.000-30.000) metres which is as per tank capacity threshold being set. In table 2 the comparison is done based to the microcontroller (MCU), Single board computers (SBC), hardware and software protocols used for data transmission and reception to monitor and actuate the water quality. Further the parameters in survey are summarized with values. The proposed work shows all the parameters range obtained as per norms defined by World Health Organization (WHO) and European Union (EU).

Table 2. Comparison with the Existing Architectures and measured parameters values

\begin{tabular}{|c|c|c|c|c|c|c|c|c|}
\hline References & Hardware & Temperature & $\begin{array}{l}\text { Potential of } \\
\text { Hydrogen }\end{array}$ & Turbidity & Conductivity & $\begin{array}{l}\text { Water } \\
\text { flow }\end{array}$ & $\begin{array}{l}\text { Water } \\
\text { Quantity }\end{array}$ & Micro controller \\
\hline [8] & $\begin{array}{l}\text { WI-FI, } \\
\text { GSM }\end{array}$ & $23{ }^{\circ} \mathrm{C}$ & $8 \mathrm{pH}$ & - & 58 & - & - & $\begin{array}{l}\text { WASPMOTE } \\
\text { (ATmega1281) }\end{array}$ \\
\hline [9] & $\begin{array}{l}\text { GSM, } \\
\text { ZIGBEE }\end{array}$ & - & 7 around & - & $67 \mathrm{~S} / \mathrm{m}$ & - & - & ARDUINO \\
\hline [7] & LCD & $33{ }^{\circ} \mathrm{C}$ & $7 \mathrm{pH}$ & - & - & - & - & NODEMCU \\
\hline [10] & $\begin{array}{l}\text { ZIGBEE, } \\
\text { GSM }\end{array}$ & $30{ }^{\circ} \mathrm{C}$ & - & $0.5 \mathrm{NTU}$ & - & - & $6.45 \mathrm{mtr}$ & XBEE \\
\hline [12] & WI-FI,GSM & $25^{\circ} \mathrm{C}$ & $8.5 \mathrm{pH}$ & - & - & - & - & $\begin{array}{l}\text { ARDUINO } \\
\text { MEGA2560 }\end{array}$ \\
\hline [11] & WI-FI,GSM & $29^{\circ} \mathrm{C}$ & - & - & $100 \mathrm{~S} / \mathrm{m}$ & - & - & ATMEGA328 \\
\hline [13] & WI-FI,GSM & $46^{\circ} \mathrm{C}$ & $7 \mathrm{pH}$ & $7 \mathrm{NTU}$ & - & - & - & ARDUINO \\
\hline
\end{tabular}




\begin{tabular}{|l|l|l|l|l|l|l|l|l|}
\hline & & & & & & & UNO R3 \\
\hline$[14]$ & WI-FI, GSM & - & $7 \mathrm{pH}$ & - & - & - & - & ATMEGA328 \\
\hline$[15]$ & $\begin{array}{l}\text { WI-FI, } \\
\text { ZIGBEE }\end{array}$ & $40{ }^{\circ} \mathrm{C}$ & $8 \mathrm{pH}$ & $5 \mathrm{NTU}$ & - & - & $6 \mathrm{mtr}$ & FPGA \\
\hline$[16]$ & $\begin{array}{l}\text { WI-FI, } \\
\text { ZIGBEE }\end{array}$ & $28{ }^{\circ} \mathrm{C}$ & $6 \mathrm{pH}$ & - & $97 \mathrm{~S} / \mathrm{m}$ & - & - & ARDUINO \\
\hline$[17]$ & Lora & $45{ }^{\circ} \mathrm{C}$ & $6.86 \mathrm{pH}$ & & - & - & - & ATMEGA328 \\
\hline$[18]$ & $\begin{array}{l}\text { WI-FI, } \\
\text { ZIGBEE }\end{array}$ & $23.85{ }^{\circ} \mathrm{C}$ & $8.6 \mathrm{pH}$ & - & - & - & - & $\begin{array}{l}\text { S2M32L151C8 } \\
\text { CHIP }\end{array}$ \\
\hline$[19]$ & WI-FI & $27.7^{\circ} \mathrm{C}$ & $6.77 \mathrm{pH}$ & $117 \mathrm{NTU}$ & - & - & - & ESP32 \\
\hline $\begin{array}{l}\text { Proposed } \\
\text { work }\end{array}$ & $\begin{array}{l}\text { WI-FI }, \\
\text { GSM }\end{array}$ & $26.25^{\circ} \mathrm{C}$ & $6 \mathrm{pH}$ & $3.8 \mathrm{NTU}$ & $96 \mathrm{~S} / \mathrm{m}$ & $3 \mathrm{gpm}$ & $5 \mathrm{mtr}$ & ESP32 \\
\hline
\end{tabular}

\section{CONCLUSION}

In this paper, the implementation of the water quality monitoring (like $\mathrm{pH}$, Turbidity, Temperature, Level), flow, and quantity of water is controlled by using ESP32 with Blynk to communicate data with the help of a phone/PC. According to survey $97 \%$ water is present in Sea and oceans only 3\% available for daily utilities. But out of this $3 \%$ only $1 \%$ is available for consumption. Thus creates necessity to save water. In addition, the advancement of technologies to achieve standards of parameter quality in less time with high efficiency is explored. The current implementation is cost-effective and beneficial for the society in the management and effective use of water resources. As a future scope, the system can be extended to the cloudbased server in smart cities for sustainable water use and to expand water samples and practical implementation in residential area in university.

\section{AUTHORS' CONTRIBUTIONS}

All authors contribute equally in this work.

\section{REFERENCES}

[1] Grossi, M., et al., A portable sensor with disposable electrodes for water bacterial quality assessment. IEEE Sensors Journal, 2013. 13(5): p. 1775-1782.

[2]. Banna, M.H., et al., Online drinking water quality monitoring: review on available and emerging technologies. Critical Reviews in Environmental Science and Technology, 2014. 44(12): p. 13701421.

[3]. Andres, L., et al., A review of in-situ and remote sensing technologies to monitor water and sanitation interventions. Water, 2018. 10(6): p. 756.

[4]. Hong, W.J., et al., Water Quality Monitoring with Arduino Based Sensors. Environments, 2021. 8(1): p. 6.

[5]. Topp, S.N., et al., Research trends in the use of remote sensing for inland water quality science:
Moving towards multidisciplinary applications. Water, 2020. 12(1): p. 169.

[6]. Bokingkito Jr, P.B. and O.E. Llantos, Design and implementation of real-time mobile-based water temperature monitoring system. Procedia Computer Science, 2017. 124: p. 698-705.

[7]. Kafli, N. and K. Isa. Internet of Things (IoT) for measuring and monitoring sensors data of water surface platform. in 2017 IEEE 7th International Conference on Underwater System Technology: theory and applications (USYS). 2017. IEEE.

[8]. Prasad, A., et al. Smart water quality monitoring system. in 2015 2nd Asia-Pacific World Congress on Computer Science and Engineering (APWC on CSE). 2015. IEEE.

[9]. Das, B. and P. Jain. Real-time water quality monitoring system using Internet of Things. in 2017 International conference on computer, communications and electronics (Comptelix). 2017. IEEE.

[10].Myint, C.Z., L. Gopal, and Y.L. Aung. Reconfigurable smart water quality monitoring system in IoT environment. in 2017 IEEE/ACIS 16th international conference on computer and information science (ICIS). 2017. IEEE.

[11].Parameswari, M. and M.B. Moses, Online measurement of water quality and reporting system using prominent rule controller based on aqua careIOT. Design Automation for Embedded Systems, 2018. 22(1): p. 25-44.

[12].Niswar, M., et al. IoT-based water quality monitoring system for soft-shell crab farming. in 2018 IEEE International Conference on Internet of Things and Intelligence System (IOTAIS). 2018. IEEE.

[13].Chowdury, M.S.U., et al., IoT based real-time river water quality monitoring system. Procedia Computer Science, 2019. 155: p. 161-168.

[14].Zainuddin, Z., R. Idris, and A. Azis. Water Quality Monitoring System for Vannamae Shrimp 
Cultivation Based on Wireless Sensor Network In Taipa, Mappakasunggu District, Takalar. in First International Conference on Materials Engineering and Management-Engineering Section (ICMEMe 2018). 2019. Atlantis Press.

[15].Zin, M.C., et al. Real-time water quality system in internet of things. in IOP Conference Series: Materials Science and Engineering. 2019. IOP Publishing.

[16].Park, J., K.T. Kim, and W.H. Lee, Recent Advances in Information and Communications Technology (ICT) and Sensor Technology for Monitoring Water Quality. Water, 2020. 12(2): p. 510 .

[17].Simitha, K. and S. Raj. IoT and WSN based water quality monitoring system. in 2019 3rd International conference on Electronics, Communication and Aerospace Technology (ICECA). 2019. IEEE.

[18].Fadel, A.A. and M.I. Shujaa. Water Quality Monitoring System Based on IOT Platform. in IOP Conference Series: Materials Science and Engineering. 2020. IOP Publishing.

[19].Mayrawan, D., et al. Development Internet of Things for Water Quality Monitoring System for Gouramy Cultivation. in 4th Forum in Research, Science, and Technology (FIRST-T1-T2-2020). 2021. Atlantis Press.

[20].Edition, F., Guidelines for drinking-water quality. WHO chronicle, 2011. 38(4): p. 104-108.

[21].Regulations, D.W., European Communities. Europe, 2007.

[22] Bhuvaneswary, N., S. Prabu, S. Karthikeyan, R. Kathirvel, and T. Saraswathi. "Low Power Reversible Parallel and Serial Binary Adder/Subtractor." Further Advances in Internet of Things in Biomedical and Cyber Physical Systems (2021): 151.

[23] Prabu, S., Balamurugan Velan, F. V. Jayasudha, P. Visu, and K. Janarthanan. "Mobile technologies for contact tracing and prevention of COVID-19 positive cases: a cross-sectional study." International Journal of Pervasive Computing and Communications (2020).

[24] Seyhan, Kübra, Tu N. Nguyen, Sedat Akleylek, Korhan Cengiz, and SK Hafizul Islam. "Bi-GISIS KE: Modified key exchange protocol with reusable keys for IoT security." Journal of Information Security and Applications 58 (2021): 102788.

[25] Nguyen, Tu N., Bing-Hong Liu, Nam P. Nguyen, and Jung-Te Chou. "Cyber security of smart grid: attacks and defenses." In ICC 2020-2020 IEEE International Conference on Communications (ICC), pp. 1-6. IEEE, 2020.
[26] Pham, Dung V., Giang L. Nguyen, Tu N. Nguyen, Canh V. Pham, and Anh V. Nguyen. "Multi-topic misinformation blocking with budget constraint on online social networks." IEEE Access 8 (2020): 78879-78889.

[27] Puttamadappa, C., and B. D. Parameshachari. "Demand side management of small scale loads in a smart grid using glow-worm swarm optimization technique." Microprocessors and Microsystems 71 (2019): 102886.

[28] Parameshachari, B. D., H. T. Panduranga, and Silvia liberata Ullo. "Analysis and computation of encryption technique to enhance security of medical images." In IOP Conference Series: Materials Science and Engineering, vol. 925, no. 1, p. 012028. IOP Publishing, 2020.

[29] Rajendran, Ganesh B., Uma M. Kumarasamy, Chiara Zarro, Parameshachari B. Divakarachari, and Silvia L. Ullo. "Land-use and land-cover classification using a human group-based particle swarm optimization algorithm with an LSTM Classifier on hybrid pre-processing remote-sensing images." Remote Sensing 12, no. 24 (2020): 4135.

[30] L. Zhen, A. K. Bashir, K. Yu, Y. D. Al-Otaibi, C. H. Foh, and P. Xiao, "Energy-Efficient Random Access for LEO Satellite-Assisted 6G Internet of Remote Things", IEEE Internet of Things Journal, doi: 10.1109/JIOT.2020.3030856.

[31] L. Zhen, Y. Zhang, K. Yu, N. Kumar, A. Barnawi and Y. Xie, "Early Collision Detection for Massive Random Access in Satellite-Based Internet of Things," IEEE Transactions on Vehicular Technology, vol. 70, no. 5, pp. 5184-5189, May 2021, doi: 10.1109/TVT.2021.3076015.

[32] L. Tan, K. Yu, A. K. Bashir, X. Cheng, F. Ming, L. Zhao, X. Zhou, "Towards Real-time and Efficient Cardiovascular Monitoring for COVID-19 Patients by 5G-Enabled Wearable Medical Devices: A Deep Learning Approach", Neural Computing and Applications, 2021 , https://doi.org/10.1007/s00521-021-06219-9

[33] L. Tan, K. Yu, F. Ming, X. Cheng, G. Srivastava, "Secure and Resilient Artificial Intelligence of Things: a HoneyNet Approach for Threat Detection and Situational Awareness", IEEE Consumer Electronics Magazine, 2021, doi: 10.1109/MCE.2021.3081874.

[34] L. Tan, N. Shi, K. Yu, M. Aloqaily, Y. Jararweh, "A Blockchain-Empowered Access Control Framework for Smart Devices in Green Internet of Things", ACM Transactions on Internet Technology, vol. 21, no. 3, pp. 1-20, 2021,https://doi.org/10.1145/3433542.

[35] Z. Guo, A. K. Bashir, K. Yu, J. C. Lin, Y. Shen, "Graph Embedding-based Intelligent Industrial Decision for Complex Sewage Treatment Processes", International Journal of Intelligent Systems, 2021, doi: 10.1002/int.22540. 